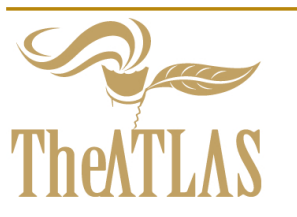

\title{
Building Transdisciplinary Urban Space (Part III): Experimental Transurbanism
}

\author{
Gerardo del Cerro Santamaría, Gerardo del Cerro Santamara, Ph.D., Dr. Soc. Sci. U.S. Fulbright Senior \\ Specialist in Urban Planning, New York Invited Professor of Urbanism and Globalization School of Architecture and Urban \\ Planning Shenyang Jianzhu University Shenyang, Liaoning, China, Email:gdelcerro@gmail.com
}

Received 15 July, 2018; Revised 10 August, 2018 Accepted 13 August, 2018

Copyright (C)2018 Gerardo del Cerro Santamaría. This is an open access article distributed under the Creative Commons Attribution License (https://creativecommons.org/licenses/by/4.0/), which permits unrestricted use, distribution, and reproduction in any medium, provided the original work is properly cited.

Available online 17 August, 2018 at www.atlas-journal.org, doi: 10.22545/2018/0104

\section{$\mathrm{T}$} his paper is the third part of a set of three papers that utilizes the classification of transdisciplinarity into theoretical, phenomenological and experimental transdisciplinarity (Nicolescu 2010) to suggest some fundamental perspectives and concepts that would be required in order to start building a transdisciplinary vision for urban space in research. In the first and second parts, we dealt with Theoretical and Phenomenological transdisciplinarity in urbanism. Theoretical transdisciplinarity in urbanism (the first paper) needs to take into account the dialectical process of scaling and the interrelationship among various spatial scales; it also needs to come to terms with the idea of relationality of urban space, a humanistic view of space and place, the "poetics of space," and a clear understanding of the idea of space in contemporary physics theories such as quantum gravity. Phenomenological transdisciplinarity as applied to urbanism, or the experience of the built space (explored in the second paper), needs to transcend both intellectualism and empiricism via Merleau Ponty's and Lefebvre's triad of spatial practices, representational space and spaces of representation, differential space, and Sojas thirdspace; it also makes use of the architectural concepts of schemata, diagram and type; further, phenomenological transurbanism uses the concept of palimpsest in order to account for the experience of time in space. This third paper deals with Experimental transdisciplinarity, which in urbanism takes into account basic quantum concepts such as non-locality, entanglement, discontinuity, non-separability, and aims at explaining processes of planetary urbanization in the so-called "Anthropocene," characterized by glocalization, hybridization, complexity, sustainability, remembrance and the reality of digital spaces.

Keywords: Quantum space, Anthropocene, planetary urbanization, glocalizing space, complexity, big data, sustainable space, memory/remembrance, digital/virtual space 


\section{Introduction}

Let us remember the words of Basarab Nicolescu on transdisciplinarity:

"There is a theoretical transdisciplinarity, a phenomenological transdisciplinarity, and an experimental transdisciplinarity. The word theory implies a general definition of transdisciplinarity and a welldefined methodology (which has to be distinguished from "methods"; a single methodology corresponds to a great number of different methods). The word phenomenology implies building models that connect the theoretical principles with the already observed experimental data in order to predict further results. The word experimental implies performing experiments following a well-defined procedure, allowing any researcher to get the same results when performing the same experiments" [1].

In this paper we shall focus on experimental transurbanism and transurban space. We operationalize "experimental" via the fundamental empirical features of our contemporary world as they relate to the research endeavor on urbanism. These features are: (1) the elements that characterize transurban reality from the perspective of the quantum nature of reality; (2) the idea that we live in a world made by us, not only from a socio-economic viewpoint, but more fundamentally from the angle of the interactions between nature, environment and society, as expressed by the idea of "Anthropocene"; (3) the spaces of "planetary urbanization," which suggests that we are dealing with an "urban world" rather than a world populated by cities; (4) the idea of globalization as the reality of a closely connected world from several perspectives (economic, political, cultural, social, etc.); (5) complexity or universal interdependence, which is akin to both the concept of anthropocene and of planetary urbanization; (6) the prominence of "big data" as a tool to manage and analyze an ever more complex world reality; (7) the idea of "sustainable space" as a strategic and ethical necessity for our world to survive; (8) the ideas of memory and remembrance, related to time, are fundamental to comprehend the nature of transurban space, simply because transurban space is space in time; (9) lastly, the idea of dig- ital and virtual spaces is critical to understand the complex world of the early 21 st century. In our view, an experimental transurbanism project needs to proceed with the underlying assumption that the above-listed features are radically transforming both the reality of our world and the experience we have of it. Therefore, transdisciplinary urbanism, an exploration into the relationships between the knowing subject and the object of knowledge, a process of discovery and design, knowledge and creativity, will pivot around these fundamental empirical features of a multi-faceted and undecidable reality.

The meaning of "experimental" used here is not that of scientific realism (ability to replicate experiments), but rather close to the concept of "experiential validation," which is often intersubjective or interactive. Philosophers who study the social character of scientific knowledge can trace their lineage at least as far as John Stuart Mill. Mill, Charles Sanders Peirce, and Karl Popper all took some type of critical interaction among persons as central to the validation of knowledge claims.

\section{The Quantum Nature of Transurban Reality}

\section{1 (Non)-locality, Entanglement, Identity}

One of the remarkable features of the microscopic world prescribed by quantum theory is the idea of nonlocality, what Albert Einstein rather dismissively called "spooky actions at a distance". This was first described in the "EPR papers" of Einstein, Boris Podolsky and Nathan Rosen in 1935, and it is sometimes referred to as the EPR (Einstein-PodolskyRosen) paradox. It was even more starkly illustrated by Bell's Theorem, published by John Bell in 1964, and the subsequent practical experiments by John Clauser and Stuart Freedman in 1972 and by Alain Aspect in 1982 [2].

Nonlocality describes the apparent ability of objects to instantaneously know about each other's state, even when separated by large distances (potentially even billions of light years), almost as if the universe at large instantaneously arranges its particles in anticipation of future events.

Despite Einstein's misgivings about entanglement and nonlocality and the practical difficulties of obtaining proof one way or the other, Irish physicist John Bell attempted to force the issue by making it 
experimental rather than just theoretical.

Bell's Theorem, published in 1964, and referred to by some as one of the most profound discoveries in all of physics, effectively showed that the results predicted by quantum mechanics (for example, in an experiment like that described by Einstein, Podolsky and Rosen) could not be explained by any theory which preserved locality. The subsequent practical experiments by John Clauser and Stuart Freedman in 1972 seem (despite Clauser's initial espousal of Einstein's position) to definitively show that the effects of nonlocality are real, and that "spooky actions at a distance" are indeed posible [3].

In theory, the concepts of entanglement and nonlocality may have applications in communications and even teleportation, although these ideas are still largely hypothetical at this stage.

Due to the effects of the uncertainty principle, the mere act of observing the properties of particles at a quantum level (spin, charge, etc), disturbs the quantum system irrevocably, and this would appear to prevent us from using this system as a means of instantaneous communication. However, Anton Zeilinger's work at two observatories in the Canary Islands has shown promising indications that entangled particles can indeed be reconstituted in a different place [4].

\subsection{Discontinuity, Non-separability, Global causality}

It becomes imperative from the onset not to think of discontinuity and continuity as binary oppositions to each other. To demonstrate our ability tothinkthe complex of the multi-dimensional structure of reality, it becomes critical to conceive of the continuity (A) and discontinuity (non-A) between the different levels of reality at the same time. As John von Breda states, it is important that we conceptualise the simultaneity or non-separability of discontinuity and continuity between the levels. Failure to see both at the same time can only result in the repetition of a reductionist position either for or against discontinuity or continuity which, in the end, may result in repetition of our ideas of 'independence' and 'detachment' from the world. To avoid such temptations, we need to accept the challenge of thinking the complex, of thinking through the simultaneity of the ruptures and continuities between the different levels-rather than to wanting to assume and defend either side of a possible dialectic of mutually exclusive or binary opposites here.

For example, if cyber-space-time is presented as another level of reality, radically different to the micro and macro-physical levels, how do we conceptualise of this level if we cannot conceive of it in terms of the concepts and laws already applicable to the micro and macro-physical levels? In other words, if cyberspace-time is to remain a fundamentally different level, it means that it cannot be understood either in terms of linearity, nor non-linearity, local causality or global causality, reversibility or non-reversibility etc. Should we use any of these concepts and laws we will contradict the earlier definition of 'level of reality' and, in the process, commit the fatal error of confusing explanans with explanandum.

Therefore, it would appear that our attempt to understand the complex structure of reality may be subverted by focusing on the fundamental differences between the different levels only, and stresses the need to expand our notion of a multi-dimensional structure of reality (ontology) with concepts and ideas (epistemology) that can facilitate our understanding of how the different levels are connected, not just separated, in a non-reductionist way. To meet this challenge of conceptualising the simultaneity between discontinuities/ ruptures and continuities / connections in nature is indeed an ambitious undertaking which certainly goes beyond the confines of this paper.

\subsection{Searching for Meaning}

"To lose the appetite for meaning we call thinking and cease to ask unanswerable questions," Hannah Arendt asserted in her spectacular meditation on the life of the mind, would be to "lose not only the ability to produce those thought-things that we call works of art but also the capacity to ask all the answerable questions upon which every civilization is founded" [5]. Indeed, that gap between what we yearn to know and what we might never know is filled with the creative restlessness responsible for almost all human achievement - our art and our science and our philosophy, those myriad tentacles 
by which we reach for the unknown knowing full well it might be unknowable, but reaching nonetheless. That perennial human impulse is what Harvard particle physicist and cosmologist Lisa Randall explores in the enormously stimulating Knocking on Heaven's Door: How Physics and Scientific Thinking Illuminate the Universe and the Modern World [6]. We follow here her discussions.

Although our quest to unravel the mystery of the universe springs from a common source, Randall points to the decided differences between sensemaking mechanisms like art, science, and religion - differences muddling which is to our great civilizational detriment:

Our universe is in many respects sublime. It prompts wonder but can be daunting - even frightening - in its complexity. Nonetheless, the components fit together in marvelous ways. Art, science, and religion all aim to channel people's curiosity and enlighten us by pushing the frontiers of our understanding. They promise, in their different ways, to help transcend the narrow confines of individual experience and allow us to enter into - and comprehend - the realm of the sublime [7].

Half a century earlier, Saul Bellow asserted in his Nobel Prize acceptance speech that "only art penetrates ... the seeming realities of this world." But however beautiful his sentiment, the reality he meant was "reality" in David Bohm's sense of humanconstructed belief systems - a distinction Randall delineates elegantly:

Art allows us to explore the universe through a filter of human perceptions and emotions. It examines how our senses access the world and what we can learn from this interaction highlighting how people participate in and observe the universe around us. Art is very much a function of human beings, giving us a clearer view of our intuitions and how we as people perceive the world. Unlike science, it is not seeking objective truths that transcend human interactions. Art has to do with our physical and emotional responses to the external world, bearing directly on internal experiences, needs, and capacities that science might never reach [8].
Science, on the other hand, seeks objective and verifiable truth about the world. It is interested in the elements of which the universe is composed and how those elements interact... Practitioners of science attempt to keep human limitations or prejudices from clouding the picture so that they can trust themselves to obtain an unbiased understanding of reality. They do so with logic and collective observations. Scientists try to objectively figure out how things happen and what underlying physical framework could account for what they observe.

A generation after Richard Feynman's meditation on the relationship between science and religion, Randall considers how the two address our quest for understanding:

The key distinction between science and religion might well be the character of the questions they choose to ask. Religion includes questions that fall outside the domain of science. Religion asks "why," in the sense of the presumption of an underlying purpose, whereas science asks "how." Science doesn't rely on any sense of an underlying goal for nature. That is a line of inquiry we leave to religion or philosophy, or abandon altogether [9].

But an unconcerned universe is not a bad thing - or a good one for that matter. Scientists don't look for underlying intention in the way that religion often does. Objective science simply requires that we treat the universe as indifferent.

Rather than disempowering, this notion of cosmic indifference is a vitalizing antidote to our human solipsism, at once grounding and elevating in reminding us that the universe doesn't exist for our satisfaction and that we are, after all, a cosmic accident - an awareness that puts even our most tumultuous existential throes into perspective. But truth and meaning, as Arendt memorably argued, are crucially different beasts, and confusing the respective questions each asks is the seedbed of trouble - a confusion at the heart of the friction between science and religion.

Randall considers how calibrating our questions can resolve that millennia-old conflict:

Science aims for a predictive physical picture that can explain how things work. The methods and goals of science and religion 
are intrinsically different, with science addressing physical reality, and religion addressing psychological or social human desires or needs [10].

Nonetheless, science has told us much about what the universe is made of and how it works. When you put together all of what we know, the picture scientists have deduced over time fits together miraculously well. Scientific ideas lead to correct predictions. So some of us trust in its authority, and many recognize the remarkable lessons of science through the ages.

Among those lessons is the idea that, as Richard Feynman put it, "it is impossible to find an answer which someday will not be found to be wrong" something essential given our propensity for selfdeception, which Faraday famously lamented. People who think science will solve all human problems are probably on the wrong track. But it does mean that the pursuit of science has been and will continue to be a worthwhile endeavor. We don't yet know all the answers. But scientifically inclined people try to pry open the universe and find them.

\section{The Anthropocene}

This section follows Yadvinder Malhi (2017) "The Concept of Anthropocene." A new epoch, the Anthropocene, is in the air. Climate scientists, geologists, archaeologists, historians, ecologists, social scientists, and philosophers are debating this concept, and it has been embraced by writers, activists, the arts, and poets.

The deliberations of an obscure scientific working group and the conventions of geological stratification are the focus of media and public attention. Prestigious prizes have been awarded to books with titles such as Adventures in the Anthropocene and The Human Age, while a plethora of other books or papers muse on, among other things, "freedom," "art," or "learning to die" in the Anthropocene. In 2011, The Economist declared "Welcome to the Anthropocene" on its front page, and in 2013 a well-received series of art exhibitions in Berlin explored "The Anthropocene Project." The moods around these discussions range from alarm and urgency, through wistful nostalgia or pragmatic management, to optimistic grasping of opportunity [11].

The Anthropocene has become a scientific and cultural zeitgeist, a charismatic mega-category emerging from and encapsulating elements of the spirit of our age. It may be a passing cultural fad or end up as something more enduring; it is used in different ways by different users, but it is undoubtedly a core aspect of contemporary thinking about the environment. There are many versions of the Anthropocene implied by different usages of the term, but amid this melee several common themes do usually emerge. The core concept that the term is trying to capture is that human activity is having a dominating presence on multiple aspects of the natural world and the functioning of the Earth system, and that this has consequences for how we view and interact with the natural world and perceive our place in it.

Part of the chimeric nature of the term Anthropocene within the natural sciences comes from its intent and origins, as it is a concept deriving from the Earth system and environmental sciences, but it adopts the nomenclature conventions of geology. The increasing informal scientific and nonscientific usage of the Anthropocene soon gained attention within the geological sciences. On one hand, some geologists were unhappy that a concept dressed up as a geological term was being widely used in such a sloppy and imprecise way and that the long timescales of the Geologic Time Scale were being adopted by and enmeshed in contemporary environmental advocacy and politics, which tend to be focused on much shorter timescales. On the other hand, some argued that a rigorous scientific case could be made for a new geological epoch, and this needed to be addressed formally.

The prospect of geological formalization was raised in 2008 by Zalasiewicz et al., who pondered whether a formal geological definition of the Anthropocene was justifiable, and if so, where and how its boundary might be placed. As a result, the Working Group on the Anthropocene (WGA) was established in 2009, with Zalasiewicz at its helm, to consider these questions and make recommendations to its parent body, the 
Subcommission on Quaternary Stratigraphy (SQS), one of 16 subcommissions of the International Commission on Stratigraphy (ICS) and its parent body, the International Union of Geological Sciences (IUGS). The IUGS is the major international scientific body for Earth scientists. The ICS is a major part of the IUGS, dedicated to defining the International Chronostratigraphic Chart, which sets out how the history of the Earth is formally partitioned [12].

Beyond the various scientific usages, whether formal or informal, the Anthropocene has spilled out of its Earth system sciences origins and has been adopted as a contemporary environmental and cultural icon. A key event in this cultural mainstreaming was the front page of The Economist in 2011, which declared "Welcome to the Anthropocene." It is employed for several purposes, but at its broadest contemporary use it encompasses a notion that the relationship of humanity with the natural world has changed (although when exactly in the past this change may have happened is a subject of intense debate), that therefore all of "nature" is touched by the hand of humanity, and that realization of the implications of this change requires a new worldview.

The phrase "... in the Anthropocene" in a title can entail a variety of meanings, ranging from "in a world that has been pushed away from a Holocene stable-state," through "in our modern, human-dominated times" or "throughout human history" to "in a complex world of human and natural entanglement." Many of these meanings have drifted some way from the original intent of signaling human domination of the Earth system. In all these various forms, the Anthropocene has become a device for re-examining and discussing the role of humanity in the natural world, on timescales from the deep past to the far future, and on scales from the intimately reflective and personal to the planetary and geological. This notion has stimulated new thinking across the sciences and humanities, and it has been adopted in wider cultural debates. It can be seen as a "charismatic mega-category" or "boundary object" that stimulates interaction and debate across a range of disciplines and perspectives. Beyond the academe, the Anthropocene has featured in numerous popular and specialist books, art exhibitions, a podcast series (Generation Anthropocene), a vibrant Twitter hashtag, and newspaper headlines and the covers of periodicals [13].

\section{The Spaces Of Planetary Urbanization}

"Planetary urbanization" is an expression originating in the work of Henri Lefebvre $(1968,1970,1989)$ that has recently been used to mark an attempt at reconceptualizing the field of urban studies from its foundations. In a brief article in Urban Constellations (2011), Neil Brenner and Christian Schmid, main proponents of the planetary urbanization approach, argue that "twentieth-century urban studies rested on the assumption that cities ("conurbations," "cityregions," "urban regions," "metropolitan regions," and "global city-regions") represented a particular type of territory that was qualitatively specific, and thus different from the "non-urban" spaces that lay beyond their boundaries." According to Brenner \& Schmid, "during the last thirty years, the form of urbanization has been radically reconfigured, a process that has seriously called into question the inherited cartographies that have long underpinned urban theory and research."

Among the recent far-reaching worldwide sociospatial transformations there are (1) the creation of new scales of urbanization (expanding metropolitan regions that create urban galaxies that often cross multiple national borders; (2) the blurring and rearticulation of urban territories, where former central functions are being dispersed outwards from central city cores into suburbanized spaces; (3) the disintegration of hinterlands, which are being reconfigured as they adopt new functions; (4) the end of the wilderness (oceans, alpine regions, rainforests, deserts, polar zones, even the atmosphere), which is being transformed in many places, and connected with the rythms of planetary urbanization, with major socio-ecological consequences [14].

According to Brenner \& Schmid, these geohistorical developments pose a fundamental challenge to the entire field of urban studies: its basic epistemological assumptions, categories of analysis, and object of investigation require a foundational recon- 
ceptualization in order to remain relevant to the massive transformations of worldwide socio-spatial organization we are witnessing today, which point toward "the urban" as representing an increasingly worldwide condition in which political-economic relations are enmeshed. This situation of planetary urbanization means, paradoxically, that even spaces that lie well beyond the traditional city cores and suburban peripheries - from transoceanic shipping lanes, transcontinental highway and railway networks, and worldwide communications infrastructures to alpine and coastal tourist enclaves, "nature" parks, offshore financial centers, agro-industrial catchment zones and erstwhile "natural" spaces such as the world's oceans, deserts, jungles, mountain ranges, tundra, and atmosphere - have become integral parts of the worldwide urban fabric.

Paralleling their critique of the traditional concept of "city," Brenner \& Schmid question the validity of the "urban age" idea. In a 2014 IJURR article (The 'urban age' in question), Brenner \& Schmid argue that, despite its long history and its increasingly widespread influence, the urban age thesis is a flawed basis on which to conceptualize world urbanization patterns: it is empirically untenable (a statistical artifact) and theoretically incoherent (a chaotic conception)."

This critique is framed against the background of postwar attempts to measure the world's urban population, "whose main methodological and theoretical conundrums remain fundamentally unresolved in early 21st century urban age discourse." (Brenner \& Schmid, 2014, 46).

Brenner's experimental project promotes a new concept of urbanity and it is more than natural that the next step should consist in submitting an alternative cognitive map that would supersede all the deficiencies and misrepresentations propagated by the discourse of the urban age. However, instead of elaborating in detail on their alternative approach, Brenner concludes his essay by "outlining a series of epistemological guidelines" penned in line with their critique of urban age discourse. In accordance with the guidelines, the urban and urbanization are perceived as theoretical categories whose defense is, to some extent, based on an attack against researchers fascinated by empirical studies, and especially by their assumed "objectivity".

Brenner \& Schmid argue that (1) the urban and urbanization are theoretical categories that need to be interpreted through their dynamics, properties and expressions; (2) the sociospatial dimensions of urbanization are variable and polymorphic and settlement-based understandings of the urban condition have become obsolete; (3) the urban is not a universal form but an historical process that has become an increasingly worldwidecfabric in which the political economy of capitalism is enmeshed; (4) urbanization involves both concentration and extensin, not just agglomerations and densely settled zones; (5) urbanization leads to increasing differences, and a new vocabulary is needed in order to reinterpret the traditional divisin rural/urban [15].

The need for a new vocabulary in urban studies is clearly stated in Implosions/Explosions. Towards a Study of Planetary Urbanization (2013), where Brenner et al build upon the methodological foundations of the scalar turn, embedding the urban within a fluidly extending landscape, and continue the critical assessment of place-based approaches to the urban question. In the book, Brenner and Schmid assert that the

"inherited analytical vocabularies and cartographic methods do not adequately capture the changing nature of urbanization processes and therefore emergent patterns require the development of new analytical approaches ... including experimental and speculative ones ... new visualizations ... a new lexicon of urbanization processes and forms of territorial differentiation" [16].

Urban studies must abandon, the authors claim, a whole array of outdated categories and concepts whose popularity in the techno-political sphere, as well as in cultural studies, is detrimental. The authors demand the removal of categories describing circumscribed locations, such as the "city", "polis", "megapolis", "edgy city", "divided city", and "town" along with the typical distinctions between "urban" and "rural" - as in the classic survey of English literature, The Country and the City by Raymond Williams - "centre" and "periphery", "centre" and "suburb." The same applies to the often investigated "boundaries", for example between the "haves" and "have-nots", as in Loren Kruger's Imagining the Edgy City: Writing, Performing, and Building Johannesburg. In sum, the authors enjoin us to replace the discrete with the continuous, the stagnant, locum-oriented with the process-oriented and 
dynamic approaches.

Another analyst of the "planetary urbanization" question is Andy Merrifield. In an IJURR article titled "The urban question under planetary urbanization" (2013), Merrifield argues that planetary urbanization is creating a whole new spatial world (dis)order, and asks: "how shall we reclaim the shapeless, formless and boundless metropolis as a theoretical object and political object of the progressive struggle? If the arena of politics has no discernible form, what would be the form of these politics? What, exactly, are urban politics?" He tries to rethink theoretically the urban question and the question of urban politics in our era of planetary urbanization, working through the political role of the urban in the light of the 'Occupy' mobilizations.

Merrifield continues that, if the urban process is open-ended and if urbanization is global and boundless, any transformative politics presumably need to be likewise. If one loses the right to the city, then one gains a capacity to forge a politics based upon the encounter - a more free-floating, dynamic and relational militancy, to be sure, yet one perhaps more apt for our age of formless metropolitanization, one more attuned to a political landscape in which new social media can and have become subversive weaponry. In any politics of the encounter, the urban is a place, a site for action, not an actor itself; to see the urban as an actor is to fetishize the urban, is to fetishize space.

The role of the urban is that of a dynamic sociospatial sphere in which the betweenness of people is "ever so much more intense, ever so much more immediate and palpable, ever more likely to erupt should that social proximity and diversity, that concentration and simultaneity, elicit human bonding or human breakdown." Meaningful encounters will almost always comprise the construction of use values as opposed to the appropriation of exchange values; and almost always will meaningful encounters unfurl on streets that now internalize the world, streets that we can rename world market streets, urban streets that express a fragile planetary ecology as well as a rapacious global economy [17].

\section{Glocalizing Space}

Following a long period of ever-increasing specialisation, a need for more relational knowledge has become apparent. The hybridisation of knowledge production has become a widespread and intensively debated issue within the scientific and academic communities. With the breakthrough of systems theory, a new episte- mological perspective has been launched that seeks to understand the whole of the mechanism at work (system-oriented) instead of focusing exclusively on fragments and parts (objectoriented).

Likewise, there is growing evidence and awareness that the earlier established, discipline-bound epistemology alone cannot effectively deal with the world's complexity. This is not to say that the production of discipline-specific knowledge is no longer relevant. Quite the opposite is stipulated here. The so-called "Mode 1" form of knowledge production does not need to be abandoned, but rather complemented by a new form of knowledge production that focuses on the combination of different types of knowledge. Such complementarity is also reflected in Basarab Nicolescu's description of transdisciplinarity: [T]ransdisciplinarity is nourished by disciplinary research; in turn, disciplinary research is clarified by transdisciplinary knowledge in a new and fertile way. In this sense, disciplinary and transdisciplinary research are not antagonistic but complementary [18].

As an object of social-scientific analysis, the city has been used to generate hypotheses of universal scope but it has rarely been used to contextualize such hypotheses, perhaps because we are accustomed to think of it as a spatial container of economic, political, social and cultural phenomena. defining the modernity and its different "post-transformations". Only urbanists adopt as an object of analysis what other social scientists use as a thematic source. The result has frequently been a problematic attribution to the city of universal qualities that all possess at all times and places, either characterizing urbanism as a specific way of life of the city (Wirth, 1938), or defining it as unit of collective consumption within the capitalist mode of production (Castells, 1972) [19]. A recent variant of the universalist argument according to which it is possible to guess in every metropolis a series of common and defining attributes is the idea of a global city that, as a center of production and control of transnational financial flows, it 
evolves in the tension of the space of the flows and the space of the places and the social dualization that they provoke. Something similar happens with the idea of global culture, which, according to some authors, tends to provoke intercultural homogenization because it "lacks context" and is not subject to any place, depending only on global communication systems. This global cacophony represents in a certain way a continuation of the structuralist way of social analysis in which the generalization in the results precedes the contextualized consideration of the processes that serve as the basis for such results

But three decades after the first analyzes of the global restructuring of capitalism emerged, the muchneeded corrections began to appear. The hypothesis of dualization, for example, identified as one of the most important universal consequences of economic restructuring in the first studies on global cities It has been questioned from different perspectives: from the point of view of production processes; from the organizational or neo-institutional point of view of urban policies; from the perspective of the welfare state; from the studies of the social structure, and also from an optics of spatial or territorial organization. Despite their disparity, all these analyzes share, implicitly or explicitly, the idea of a relational analysis of social processes that, on the one hand, emphasizes the complexity of localized contexts of social action and, on the other, it associates the impacts of globalization with metaphors of fragmentation and juxtaposition, not dualization. What we might call a strong version of the thesis of globalization (that is, the similar impact, unilinear and not mediated, of "global" factors in different contexts) is therefore hardly defensible if the city is conceived as a global network contextualized (but not spatially contained) of societal flows that not only operate locally but at different spatial scales.

The perspective is thus transferred from "globalization" to the global location and what we would call, in direct translation of the English term, glocalization, a dissonant but fortunate neologism that can become a symbol of the necessary convergence between excesses explanations of the global arguments and the analytical limitations of local perspectives A growing globalization of (or greater and more widespread access to) the flows, means or channels through which the information is transmitted can therefore be assumed, but not a global homogenization of results in specific territories or places; On the contrary, globalization brings us closer to the experience of cultural diversity.

The immediate consequence of all this is a greater attention to the idea of place (in its different territorial scales) as an instrumental axis of social power without it being necessary to interpret the radical contemporary social and territorial transformations as the origin of a new medievalization of the world due mainly to the supposed loss of control of national states over their traditional functions. This is not the time to return to the Weberian path, but to generically consider the old idea of urbanism understood in a cultural context, according to which "cities conform contexts in which cultures and societies are produced and transformed, as well as their own Cities are produced and transformed by those cultures and societies. "If the global is constructed and transformed into specific territories, the local also contributes to the production of the intersection of multiple social relations, processes, structures, and representations. This growing attention to the location of social processes seems to coincide with a certain resurgence of interpretations of the city as a scenario for cultural production and consumption. Although it is not a new phenomenon at all, its intensity and the historical context in which it develops do provide elements for its detailed analysis. On the one hand, the collective legitimization of the cultural use of urban space has been extended, with its clear reference in the conservation and rehabilitation initiatives of historic centers, which have become the first space for cultural use in many contemporary western cities, and in a powerful tourist attraction.

In addition to the historic centers, the entire urban fabric is being provided with new spaces dedicated to cultural consumption (museums, galleries, convention and convention centers, concert halls, cultural hypermarkets) and, simultaneously, many traditional spaces for consumption they acquire a certain cultural aesthetic. Consequently, culture emerges as the subject of business and political strategies with an importance that it had lacked until now in contemporary metropolises, although not every metropolis acquires the rank of "global" ( as a main node in the international financial network), it can be said that a good number of them participate in transnational cultural flows, and produce and experience the specific consequences of such flows, visible at the local level in the presence and influence of companies, workers, tourists and foreign products. 


\section{Spaces of Complexity}

This section follows Nicolescu, Basarab (2010) "Methodology of Transdisciplinarity: Levels of Reality, Logic of the Included Middle and Complexity." From a transdisciplinary point of view, complexity is a modern form of the very ancient principle of universal interdependence.

This recognition allows us to avoid the current confusion between complexity and complication. The principle of universal interdependence entails the maximum possible simplicity that the human mind could imagine, the simplicity of the interaction of all levels of reality. This simplic- ity cannot be captured by mathematical language, but only by symbolic language. The mathematical language addresses exclusively to the analytical mind, while symbolic language addresses to the totality of the human being, with its thoughts, feelings and body. In the context of our discussion, what is important to be understood is that the existing theories of complexity do not include neither the notion of levels of Reality nor the notion of zones of non-resistance. However, some of them, like the one of Edgar Morin, are compatible with these notions. It is therefore useful to distinguish between the horizontal complexity, which refers to a single level of reality and vertical complexity, which refers to several levels of Reality. It is also important to note that transversal complexity is different from the vertical, transdisciplinary complexity. Transversal complexity refers to crossing different levels of organization at a single level of Reality [20].

From a transdisciplinary point of view, complexity is a modern form of the very ancient principle of universal interdependence. This recognition allows us to avoid the current confusion between complexity and complication. The principle of universal interdependence entails the maximum possible simplicity that the human mind could imagine, the simplicity of the interaction of all levels of reality. This simplic- ity cannot be captured by mathematical language, but only by symbolic language. The mathematical language addresses exclusively to the analytical mind, while symbolic language addresses to the totality of the human being, with its thoughts, feelings and body.

For Edgar Morin (2005), since a paradigm of simplification controls classical science, by imposing a principle of reduction and a principle of disjunction to any knowledge, there should be a paradigm of complexity that would impose a principle of distinction and a principle of conjunction. In opposition to reduction, complexity requires that one tries to comprehend the relations between the whole and the parts. The knowledge of the parts is not enough, the knowledge of the whole as a whole is not enough, if one ignores its parts; one is thus brought to make a come and go in loop to gather the knowledge of the whole and its parts. Thus, the prin- ciple of reduction is substituted by a principle that conceives the relation of whole-part mutual implication. The principle of disjunction, of separation (between objects, between disciplines, between notions, between subject and object of knowledge), should be substituted by a principle that maintains the distinction, but that tries to establish the relation. The principle of generalized determinism should be substituted by a principle that conceives a relation between order, disorder, and organiza- tion. Being of course that order does not mean only laws, but also stabili- ties, regularities, organizing cycles, and that disorder is not only dispersion, disintegration, it can also be blockage, collisions, irregularities [21].

\section{Big Data}

This section follows the discussion by Mathieu Helie (see reference 22). The aim of many Urban Complexity centers to reveal hidden regularities in the organisation of cities by using methods at the intersection of Complexity Science and Big Data Analytics. This new research area allows us to better anticipate systemic behaviour that result from the many interactions of all the components that make up a city, including people and infrastructures. The research consists of connecting and analysing various 
dataset types across different countries and cities in order to build, validate and test hypotheses. The different types of data sets range from mobile phone and social media data to census and survey data, which are utilised and combined according to their specific strengths.

Examples of ongoing projects include the discovery of a fundamental scaling law that describes the movement of people in cities, the relation between the built-up form of a city and its socio-economic functioning, and the prediction of changes in the socioeconomic mix of urban neighbourhoods. The revealed regularities are the basis for the formulation of constraints for urban planning and design processes. Christopher Alexander showed in A City is not a Tree (Alexander, 1965) that social and economic networks formed complex semilattice patterns, but that people who observed them limited their descriptions to a simple mathematical tree of segregated parts and sub-parts, eliminating connections in the process. In attempting to plan for urban structure, a single human mind, without a supporting computational process, falls back on tree structures to maintain conceptual control of the plan, thus computing below spontaneous urban complexity, a phenomenon that is consistent with Wolfram's theory of computational irreducibility of complex systems [22].

Nikos A. Salingaros later detailed the laws of urban networks in Theory of the Urban Web. Network connections form between nodes that are complementary, and therefore the complexity of networks depends on an increasing diversity of nodes.

Salingaros describes the urban web as a system that is perpetually moving and growing, and in order to do this the urban tissue has to grow and move with it. Consider for example the smallest social network, the family. Debate over accessory units or "granny flats" has intensified as normal aging has forced the elderly out of their neighborhoods and into retirement complexes, while at the other end of the network young adults entering higher education or the labor market vanish from a subdivision, leaving a large homogeneous group of empty-nesters occupying what was once an area full of children, and often forcing school closures (a clear expression of unsustainability) [23].

These social networks grow more complex with increasing building density, but a forced increased in density does not force social networks to grow more complex. For instance the spontaneous settlements of slums in the developing world show remarkable resilience that authorities have had difficulty acknowledging.

Because of squalid living conditions authorities have conducted campaigns to trade property in the slum for modern apartments with adequate sanitary conditions. To the authorities' befuddlement some of the residents later returned to live in the slum in order to once again enjoy the rich social networks that had not factored in the design of the modern apartments and neighborhoods, demonstrating that the modern neighborhoods were less socially sustainable than the slums. In commercial networks, space syntax research, using a method for ranking nodes of semi-lattice networks, has shown that shops spontaneously organize around the multiple scales of centrality of the urban grid at its whole, creating not only commercial centers but a hierarchy of commercial centers that starts with sporadic local shops along neighborhood centers and goes all the way to a central business district located in the global center of the spatial network [24].

The distribution of shops is therefore a probabilistic function of centrality in the urban grid. Because the information necessary to know one's place in the hierarchy of large urban grids exceeds what is available at the design stage, and because any act of extension or transformation of the grid changes the optimal paths between any two random points of the city, it is only possible to create a distribution of use through a feedback process that begins with the grid's real traffic and unfolds in time.

Although they may appear to be random, new buildings and developments do not arise randomly. They are programmed when the individuals who 
inhabit a particular place determine that the current building set no longer provides an acceptable solution to environmental conditions, some resulting from external events but some being the outcome of the process of urban growth itself. It is these contextual conditions that fluctuate randomly and throw the equilibrium of the building set out of balance. In order to restore this equilibrium there will be movement of the urban tissue by the addition or subtraction of a building or other structure. In this way an urban tissue is a system that fluctuates chaotically, but it does so in response to random events in order to restore its equilibrium.

\section{Sustainable Space}

A major effort to halt the effects of climate change and support environmental sustainability has developed worldwide at the urban and regional levels around the concept and practice of "sustainable city" and its associated planning practices.

A sustainable city, or ecocity, is a city designed with consideration of environmental impact, inhabited by people dedicated to minimization of required inputs of energy, water and food, and waste output of heat, air pollution - $\mathrm{CO}_{2}$, methane, and water pollution. It is agreed that Richard Register first coined the term "ecocity" in his 1987 book, Ecocity Berkeley: Building Cities for a Healthy Future. Other authors, planners and practitioners who have led the field of sustainable cities are architect Paul F Downton, and authors Timothy Beatley and Steffen Lehmann, who have written extensively on the subject [25].

Climate change and global warming have the highest human impact in populated areas such as urban regions. These large communities provide both challenges and opportunities for environmentallyconscious developers, and there are distinct advantages to further defining and working towards the goals of sustainable cities. It might sound paradoxical, but, contrary to common belief, urban systems can be more environmentally sustainable than rural or suburban living. The current global trend to more dense, urban living would provide an outlet for social interaction and conditions under which humans can prosper. With people and resource located so close to one another it is possible to save energy and resources in areas such as food transportation, infrastructure, energy delivery and mass transit systems. Thus, one could say that urbanization shows a potential to facilitate the management, and perhaps control, of climate change.

Everyone who loves nature fears losing it. But "nature" is not "the other" in an increasingly urban world, but a new way of thinking about the sustainable integration of all sentient beings and the environment. What we call "environment" is always a mixture of nature and culture. People and landscapes are molded together. Nature and culture resemble hydrogen and oxygen in water: together they create new and exciting possibilities. Nowhere is this interaction better expressed than in the cities. To discover how this idea can work in the "Anthropocene" (the contemporary era of massive and radical transformation of the planet by the human being), we need study and transformation, vision and practice.

We need an "urban practice of the natural" that, as suggested by the American poet and ecological activist Gary Snyder, combine the knowledge of Western philosophy, poetry and natural sciences with the wisdom and spiritual techniques of Native American and Asian cultures. The old ways that supported human life for a hundred thousand years acquire a new and fundamental relevance in the achievement of a sustainable world. But how can we practice the natural in cities? Is not it a contradiction in terms? It is not, although it requires a change of mentality. The "natural" does not necessarily mean "nature". The natural is about creativity, emergence and the self-organizing power of complex adaptive systems. The natural thing is the preservation of the world, sustainability, and this attitude is necessary especially in cities. If so, then we must align our thoughts and efforts accordingly, beginning with education. Sustainability requires ecological literacy, so let's incorporate it into the curriculum from elementary school to university. Each neighborhood of a city is full of lessons about natural and human history, a living museum that lacks signage and teachers. It's all there.

Cities also offer a splendid place for imaginative ecological designs and to articulate a vision of the "ecology of reconciliation," in which the built environment would be configured to meet the needs of multiple species in addition to ours. It is not diffi- 
cult to extend this idea in many directions. Inspiring instances can already be found in many cities, including New York, where the High Line Park was created along the bed of an abandoned elevated railroad and "pocket parks" have emerged in brownfields or vacant lots along the river Bronx and other careless places. Such projects, accessible, accessible and of human scale, are often promoted and maintained by people in the neighborhood.

I insist that it is a change of mentality and perception, and it helps us to think about the ideal of the city as a work of art. The idea of art as a form of autonomous individual expression (as opposed to craftsmanship made in the name of a patron, be it king or church) arose at the same time as the romantic notion of nature. In the romantic tradition, which includes most of the avant-garde, art is directly related to nature under the guise of the creative genius that replaces academic conventions and other forms of external control. Both art and nature are, therefore, ways to repair the damage that society has inflicted on the individual and the environment.

But while nature is something that is "out there", art is the human production closest to us. The urban is art, or it can be. It is a place where the existential state of physical matter that comprises the universe that exists beyond our attempts to rule over it - true nature in all its frightening and inanimate alterity - can be revealed virtually at the intersection of physical matter and the conscious being, the relation of the objective form and the subjective content that constitutes a work of art.

The romantic vision of nature, the aesthetic idealization of the exurban areas, has had disastrous consequences for the ecological health of the planet. The invasion of wild areas in distant places allows us to justify our abuse, neglect or exploitation of local nature, which seems less dignified and less atrocious to victimize. The ideal of "wild" or "natural" life helps to situate the urban as deserving of aesthetic contempt, and induces urbanites to tolerate, on a daily basis, many of the problems of cities. The human conscience is trapped in a mode of romantic ecological consumption that makes the forest a showcase and allows the environment of a showcase to be experienced as the temple of nature and thus consume the desert and forests. City and nature are very close ideas in reality. Both are organized complexity and distant from self-regulated harmony.
The concept of nature as an autonomous and harmonious set of internal self-regulated relationships that always return to harmony and equilibrium insofar as they are not disturbed by man or humanity is a misconception. Nature is, in fact, a waste without measure. No doubt, at this moment, there is a black hole that devours a solar system that contains a planet with a rich ecosystem and that includes the emergent life of the intelligent octopus that will soon enter the space age and explore the rest of its solar system. Each season, the fish produce millions of offspring with only a few survivors. Throughout natural history, there have always been species that have had the advantage of unbalancing everything. This happened, for example, with the emergence of eukaryotes that filled the oxygen atmosphere making it flammable and causing the extinction of millions of species due to the decrease of several dioxides in the atmosphere. Asteroids hit the Earth, annihilating millions of species, and so on.

Has anyone noticed that the idea of nature as a harmonious, wise and self-regulating mechanism of Mother Earth is identical with the idea of the capitalist market? The neoliberal ideology says that the economy is a self-regulated system that always returns to balance and harmony. To intervene in this system, according to history, is to interrupt it and invite disaster by not obeying the anonymous wisdom of the economy. The case is similar in ecology. Because nature is considered harmoniously self-regulating, any technological intervention in the climate is considered a probable catastrophe (a subject of many science fiction-driven novels and films).

Darwin does not celebrate the harmony of nature, but how small differences can suddenly become significant differences as a result of geographic drift and climate change, but also how all kinds of crossspecies and cross-species relationships generate new vectors of evolution that lead to totally surprising directions. Something very similar to what happens in the city as organized complexity. Therefore, "urban ecology" is the way of thinking about the natural in the contemporary era. The anthropocentrism that underlies the dominant ecological vision does not treat nature as a community to which we belong but as an external ideal that must be saved ... to save ourselves. This is the main ideological obstacle that prevents the achievement of sustainability. 


\section{Space of Memory and Remembrance}

Transurban experimental space is space in time, and societies keep an idea of the past through ritualising bodily practices. In other words, social memory is not only preserved throughout time by conscious efforts of citizens (who, avoiding to forget key dates, events, and processes, would employ narrative devices and inscribe that past in the present-time conscience collective), but also by the actual practices which those citizens incorporate through collective rituals and which are reflected in their bodily behavior.

In general terms, I think this idea by Paul Connerton in How Societies Remember (HSR) is convincing, and his effort to define a new theoretical and empirical object for the study of social memory turns to be quite successful [26]. Nevertheless, I would like to develop two points of critique. The first one concerns the deliberate apolitical tone of the author's analysis of rituals. I shall argue that Connerton's study would have benefitted from taking into account a "politics of memory." The second critique has to do with the excessively passive role that individuals play in the author's schema. By presenting human bodies as vehicles of past traditions, Connerton neglects, for example, the potentials for rupture with such past that individuals may also enact through their bodies.

Connerton recognizes a wide variety of ways through which social memory can be preserved (gossip in villages, life histories, oral histories, narration), but his emphasis is upon what he calls "habitmemory". Habit-memory is not the type of mental exercise in which one recalls one's life history, or the remembrance of past external things. Unlike these two modes of memory, which operate, so to speak, through the brains of the agents, Connerton points out that there is another memory which is unconsciously transmitted through our bodies by means of an "accumulative practice of the same" [27].

Connerton applies his ideas to rituals. By examining the meaning of rituals, Connerton makes emphasis upon their performative character. The fact that ritual occasions keep exactly the same form (same characters, same words, same procedures, same symbols involved) in each performance is evidence that, implicitly -and some times explicitly- rituals serve the purpose of remembering the past. Thus, rituals accomplish a function which goes beyond the ritual moment: they represent a continuity with prior states of things, processes, or events.

Connerton rejects psychoanalytic, sociological, and historical approaches to rituals because, according to him, all "seek the meaning of rituals behind the surface". Instead, the performance of a ritual represents a message in itself. The author portrays rituals in a way that highlights their mnemonic thrust, something that cultural functionalist theory had neglected. Rites of passage would not only imply, for example, a change of status for particular social actors (as in Turner), but precisely the "reenactment of a narrative of events held to have taken place at some time in the past" [28].

Thus, Connerton's vision on rituals is useful to explain why such ceremonies cannot change formally over time. And it may also explain why there occurs a complicated process of deliberation before making the decision of changing any of the ritual's elements. The resolution undertaken by the Catholic Church in the sixties of allowing the celebration of the mass in modern languages, with the priest facing the public, and not exclusively following the Latin rite, was preceded by a long, careful process of discussions among the members of the Catholic hierarchy. During the debates, the importance of what Connerton calls "accumulative practice of the same" was indeed claimed by some sectors of the Church (many of them followers of the french archbishop Marcel Lefevre), which rejected the decision of the pope, still today celebrate the mass in the old way, and even intend to separate from Rome's rule after what they considered to be a betrayal to the original Peter's Church.

At this point one question arises. If the meaning of a ritual has to be found in its relevance for keeping collective memory alive, is not this another way of maintaining the status quo, of preserving the actual social order by the very fact of claiming continuity with a past which has to continue? Furthermore, does not this position place Connerton very much in the same theoretical line of the functionalists that he seems to reject? Indeed, Connerton recognizes that rituals are (or can be) legitimating performances. But, if this is so, I do not see how he can reject Winch's idea that habits and rituals are rule-governed behavior [29]. Does not it seem as if Connerton sometimes moved within the difficult, ambiguous space of accepting the role of politics in 
the construction of ritualization, and at the same time excluding it from his analysis?

More specifically, one is tempted to think that the formal importance of the elements of a ritual stands behind its political relevance. In other words, when rituals explicitly pursue the function of preserving a particular social order, the performative aspects can be subject to variation. This could occur because the political intention of the ritual clearly goes against a prevailing portion of the past, or because the political function of the ritual can be improved through some formal changes. At some point in his argumentation, Connerton pictures rituals as "compensatory strategies." I would tend to think that such strategies are often determined in the political sphere.

To take the example of the Catholic Church mentioned above, the decision of changing the mass rite was made in a historical moment of decreasing social influence of the Church. One could think that the decision was finally made as a means of adapting the Church's ritual practices to the current times. By allowing priests to change the tradition and celebrate the mass in English, French, Spanish, or Italian they probably intended to identify with people's own linguistic practices and codes. By making the priest physically face the attendants to the mass, they probably wished to substitute a symbolic element of visibility, transparency and closeness for one which involved a greater deal of obscurity, mystery, and authoritarianism.

On the other hand, it is quite common to observe how a political regime establishes or restores rituals which accord its ideological aims. The restoration of democracy in Spain in 1976 came along with the restoration of monarchy. The unanimous intention of political elites at that historical moment was to stress the connection with the monarchic past (not with the republican democratic past-from 1931 to 1939), and, reversely, to blur, suppress, and even prohibit many symbols and rituals which the collective memory associated with the Francoist regime.

Connerton is perfectly aware of this political side of social memory. However, his explicit rejection to discuss it makes the reader feel that the author's conceptual construction and argumentation remain artificially neutral. Indeed, Connerton presents rituals as the symbolic connection between presents and pasts that are too abstract entities (when both were and actually are socially constructed), serving a collective memory which really involves different social cleavages.

Nevertheless, Connerton does not reduce his habitmemory to commemorative ceremonies. This is perhaps his main originality. He claims that societies remember through everyday-life bodily practices, which, again, reflect such societies's past. Connerton includes, among others, the brilliant example of Jews and Italians "hand language" in order to illustrate his point. By noting the differences between both traditions (the referential character of Jewish gestures, and the notational of the Italian ones), Connerton shows how bodily practices are socially and historically rooted. Furthermore, these practices need not to be framed in explicit rituals that celebrate prominent past events. The fact that they are performative and repetitive makes them eligible as exercises of re-enacting the past, in Connerton's view.

It is true that everyday reality exhibits a large number of minuscules, ephemeral individual performances that are unconsciously incorporated to our bodily behavior from the deposit of our collective past. Connerton gives multiple examples of this. However, one feels that he concedes the past excessive importance as the origin of individual present behavior. One could more fairly assess the role of the past by taking into account that there are many occasions in which individuals' bodies do not act as mere vehicles of collective traditions.

In my view, one could argue that much of the power of the past over the present may be neutralized by the various ways in which individuals re-create their own reality (which may, but needs not, be shared by a collectivity). By combining elements of different pasts in different traditions, individuals or small groups are able to establish practices that purposefully aim to manifest against prevalent symbols or codes of behavior. For example, one is reminded of the hippie movement in the sixties, which arose as a generalized youth protest against the prevailing Western societies's value system.

To take Connerton's own examples, not always the transmission of table manners from one generation to the next happens to be effective. Some individuals may decide to separate from these bodily codes as a means of showing non-conformity with these particular practices, or because they simply feel that such practices are being imposed. Connerton suggests that we unconsciously incorporate bodily practices 
to our usual behavior. I would add that sometimes individuals exert a capacity to break the links with the expression of social memory in a conscious way. In some cases, these newly incorporated habits become themselves a tradition and are remembered as such (for example, hippie rites, which involve a particular body language and clothing which has not fundamentally changed since the sixties). In some other cases, the individual reactions become pervasive in the individual who initiated them and typical in the bodily behavior of that particular individual (ways of walking, of smiling, hands movements). Indeed, these particularities combined help many times to identify this or that person from a collectivity.

In the performative ceremonies which rituals represent as well as in the minuscules, everyday actions effected through our bodies, Connerton sees a constant actualization of significant portions of the past. I think he is generally right. However, I also think that the necessary sharpness that Connerton develops in his book for the sake of innovation immoderately narrows his theoretical focus.

\section{Digital and Virtual Spaces}

This section follows the discussion by Ridell and Zeller in International Communication Gazette (see note 30). Given that everyday urban uses of media and technologies become easily routinised and thereby taken for granted, we are talking about a process that some critical geographers approach in terms of 'automatic production of space' - a process that is conditioned by the 'sinking of software' into our collective 'technological unconscious' [30]. It is beyond the scope of this introduction to go into an indepth discussion of the notion of non-representation that lies behind these observations [31].

It should be stated, however, that our reading of this special double issue's contributions has resonance with the nonrepresentational view of urban spatial power. More generally, it is our contention that in an era of expanding urbanisation and ever more pervasive technologymediation, researchers of communication and media studies are hard pressed to develop fresh approaches to the complex power-relatedness of people's outdoor media use and habits. To start with, there is the general and prolonged marginality of forms and practices of urban audience activities as a research topic in communication and media studies. It can be claimed, in fact, that the situation today does not differ too drastically from the beginning of the 1980s, when Dafna Lemish argued that scholarly attention should be devoted to the phenomenon of viewing television in public places [32].

Research on television viewing had focused almost exclusively on the home context, and neglected locations such as department stores, store cafeterias, airport lobbies, barbershops, college lounges and bowling alleys. Culturally oriented audience research has concentrated firmly on the home as the primary spatial context for people's media relations. On the basis of the articles in this special double issue, however, it is obvious that extending the scholarly gaze beyond the household walls has not only become inescapable, but is gradually taking shape in the field of media audience scholarship, too.

A more particular topic of future research concerns the nature and role of different spatial platforms as arenas for democratic public communication.

Communication in this public arena lacks any real reciprocity. Here, one option for future analysis could be to expand and reframe Gitlin's idea of 'public sphericules' in the present-day digitalised urban context, and relate it to the notion of 'media territories' as constructed in people's media-related activities. This would open up possibilities to compare how diversely mediated urban environments function as public spaces, not only in the sense of visibility to others but also in the sense of collectivity as defined by Hannah Arendt (1958) [33]. In this connection, a useful concept in addition to 'audience' would be 'public' - especially if defined in the spirit of the classical studies by Robert E Park and Herbert Blumer [34].

One major set of future challenges concerns fruitful research methods in the field of mediated urbanism studies.

Obviously, diverse ways of generating, combining and analysing empirical materials 
can be employed usefully, as is demonstrated by those articles here that report and discuss case studies. What we would like to especially emphasise in this connection is the need for self-reflection in terms of theoretical com- mitments and methodological implications. As researchers, we should be aware of and assess the specific ways that the concepts we use 'sensitize' (Blumer, 1986 [1969]) and politicize (or not) the phenomena we want to deal with [35].

\section{Concluding Remarks}

In this paper we have focused on experimental transurbanism and transurban space. We operationalized "experimental" via the fundamental empirical features of our contemporary world as they relate to the research endeavor on urbanism: (1) the elements that characterize transurban reality from the perspective of the quantum nature of reality; (2) the idea that we live in a world made by us, not only from a socio-economic viewpoint, but more fundamentally from the angle of the interactions between nature, environment and society, as expressed by the idea of "Anthropocene"; (3) the spaces of "planetary urbanization," which suggests that we are increasingly dealing with an "urban world" rather than a world populated by cities; (4) the idea of globalization as the reality of a closely connected and interactive world from several perspectives (economic, political, cultural, social, etc.); (5) complexity or universal interdependence, which is akin to both the concept of anthropocene and of planetary urbanization; (6) the prominence of "big data" as a tool to manage and analyze an ever more complex world reality; (7) the idea of "sustainable space" as a strategic and ethical necessity for our world to survive; (8) the ideas of memory and remembrance, related to time, which are fundamental to comprehend the nature of transurban space, simply because transurban space is space in time; (9) lastly, the idea of digital and virtual spaces is critical to understand the complex world of the early 21 st century.

We tried to show that an experimental transurbanism project needs to proceed with the underlying assumption that the above-listed features are radically transforming both the reality of our world and the experience we have of it. Therefore, transdisciplinary urbanism, an exploration into the relation- ships between the knowing subject and the object of knowledge, a process of discovery and design, knowledge and creativity, has to pivot around these fundamental empirical features of a multi-faceted and undecidable reality. Ours is an approximation to empirical reality, and therefore indeterminate, uncertain, incomplete and undecidable. This does not mean that research and knowledge are not possible or fatally flawed; it simply means that they will always be subject to further questioning and critique. As Heinsenberg put it, reality is the continuous fluctuation of the experience as captured by consciousness. In that sense, it can never be identified to a closed system.

Funding: This research received no external funding.

Conflicts of Interest: The author declare no conflict of interest.

\section{References}

[1] Nicolescu, Basarab (2010) "Methodology of Transdisciplinarity: Levels of Reality, Logic of the Included Middle and Complexity" Transdisciplinary Journal of Engineering and Science, 1(1), 19-38.

[2] "If [a hidden variable theory] is local it will not agree with quantum mechanics, and if it agrees with quantum mechanics it will not be local. This is what the theorem says." John Bell, Speakable and Unspeakable in Quantum Mechanics, Cambridge University Press, 1987, p. 65. Stuart J. Freedman; Clauser, John F. (1972) "Experimental Test of Local Hidden-Variable Theories". Physical Review Letters. , 28(14): 938-941. Aspect, A., P. Grangier, and G. Roger (1982) Experimental Realization of Einstein-Podolsky-Rosen-Bohm Gedankenexperiment: A New Violation of Bell's Inequalities, Physical Review Letters, Vol. 49, Iss. 2, pp. 91-94. This section and the next follow the discussion found at https://www.physicsoftheuniverse.com/topics _quantum_nonlocality.html.

[3] Stuart J. Freedman; Clauser, John F. (1972). Experimental Test of Local Hidden-Variable Theories. Physical Review Letters. 28(14): 938-941.

[4] Zeilinger, A. (02018). Quantum Teleportaton, Onwards and Upwards, Nature Physics, 14(1), January, $3-4$.

[5] Arendt, H. (1981) The Life of the Mind, New York: Mariner Books, p. 68.

[6] Randall, L. (2012). Knocking on Heaven's Door: How Physics and Scientific Thinking Illuminate the 
Universe and the Modern World, New York: Ecco, p. 33 .

[7] Ibid. p. 45.

[8] Ibid. p. 62.

[9] Ibid. p. 81.

[10] Ibid. p. 96.

[11] Vence, G. (2015). Adventures in the Anthropocene, New York: Milkweed; Ackerman, D. (2015) The Human Age. The World Shaped by Us, New York: W. W. Norton. This section follows Yadvinder Malhi (2017), The Concept of Anthropocene, Annual Review of Environment and Resources 42, pp. 77-104.

[12] Zalasiewicz, J. et. Al. (2018). The Anthropocene as a Geological Time Unit, New York: Cambridge University Press, forthcoming.

[13] Generaton Anthropocene https://www.genanthro. com

[14] Brenner, N. and C. Schmid, (2011). Planetary urbanization. In M. Gandy (ed.), Urban Constellations, Jovis, Berlin, passim.

[15] Brenner, N., \& C. Schmid, (2014). The 'urban age' in question. International Journal of Urban and Regional Research, 38(3), 731-755, passim.

[16] Brenner, N. (ed.) (2013). Implosions/Explosions. Towards a Study of Planetary Urbanization, Berlin: Jovis, p. 334 .

[17] Merrifield, A. (2013). The urban question under planetary urbanization. International Journal of Urban and Regional Research, 37(3), 909-22, passim.

[18] Nicolescu, Basarab (2002) Manifesto of Transdisciplinarity, State University of New York Press, New York, USA, translation from the French by KarenClaire Voss, p. 45.

[19] Wirth, L. (1938) Urbanism as a Way of Life, American Journal of Sociology, 44(1), 1-24; Castells, M. (1979) The Urban Question. A Marxist Approach, Cambridge, MA: The MIT Press.

[20] Morin, Edgar, (2005). On Complexity. Cresskill, NJ: Hampton Press, p. 59. This section follows Nicolescu, Basarab (2010) "Methodology of Transdisciplinarity: Levels of Reality, Logic of the Included Middle and Complexity" Transdisciplinary Journal of Engineering and Science, 1(1), 19-38.

[21] Morin, E., Ibid. p. 83.

[22] Alexander, Christopher, (1965). A City is not a Tree, Architectural Forum, vol. 122 no. 2. This section follows the discussion by Mathieu Helie found at http://emergenturbanism.com/2009/05/11/thefundamentals-of-urban-complexity/

[23] Salingaros, Nikos, (1998). Theory of the Urban Web, Journal of Urban Design, vol. 3.
[24] Hillier, Bill, (1996). Space is the Machine, Cambridge University Press, UK.

[25] Register, R. (1987). Ecocity Berkeley: Building Cities for a Healthy Future, Berkeley: U. Of California Press.

[26] Connerton, P. (1989). How Societies Remember, New York: Cambridge University Press, p. 46.

[27] Ibid. p. 59.

[28] Ibid. p. 72.

[29] Ibid. p. 96.

[30] Thrift N and French S. (2002). The automatic production of space. Transactions of the Institute of British Geographers 27(3), 309-335. This section follows the discussion by Ridell and Zeller in International Communication Gazette 75(5-6), pp. 437-451.

[31] Thrift N. (2007). Non-representational Theory: Space, Politics, Affect. London: Routledge.

[32] Lemish, D. (2010). Screening gender in children's $T V$ : The views of producers around the world. New York and Abingdon: Routledge.

[33] Arendt, H. (1958, 1998). The Human Condition, Chicago: University of Chicago Press.

[34] Park, R. (1972). The Crowd and the Public and Other Essays, Chicago: University of Chicago Press; Blumer, H. (1948). "Public opinion and public opinion polling." Amer. Soc. Rev. 13: 542-544.

[35] Blumer, H. (1954). What is Wrong with Social Theory, American Sociological Review 18, 3-10.

\section{About the Author}

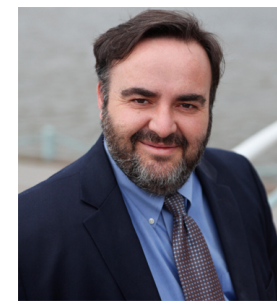

Gerardo del Cerro Santamaría, is a U.S. Fulbright Senior Specialist in Urban Planning from New York. He is an Invited Professor of Urbanism and Globalization at the School of Architecture and Planning, Shenyang Jianzhu University in China. He has been a Visiting Professor at MIT and a Visiting Scholar at Columbia University, as well as Research Professor of Planning and Megaprojects at The Cooper Union for the Advancement of Science and Art in Manhattan, where he also served as Senior Executive Director of Strategic Planning and Innovation. As of Fall 2018 he will be serving as a Senior Advisor 
to the Planning of the Jing Jin Ji Megalopolis in China. Del Cerro has published several books, journal articles and encyclopedia entries. He is the author of Bilbao. Basque Pathways to Globalization (2007); editor of and contributor to Urban Megaprojects. A Worldwide View (2013); and author of "Megaprojects in Global Context" in The Oxford Handbook of Megaproject Management (2017). He has a background in Science, Music Theory, Logic and Philosophy of Science and holds Ph.D.'s from the New School for Social Research in New York (Political Economy) and the Universidad Autónoma de Madrid, Spain (Economic Sociology). 